\title{
Abgekürzt zitierte Rechtsquellen
}

amerik. UCC amerik. USA

Avant-projet cc

California cc dän. Minderjährigengesetz

deut. BGB

engl. SGA 1893

Entwurf Meijers

franz. cc

ital. cc

Louisiana cc

nied. BW

norw. Minderjährigengesetz

öst. ABGB

schwed. Elterngesetz schweiz. OR schweiz. ZGB skand. Kaufgesetze

skand. Vertragsgesetze

span. cc span. c. com. ungar. ZGB
$=$ Amerikanischer Uniform Commercial Code, 1958

= Amerikanischer Uniform Sale of Goods Act, 1906 (von 37 Staaten der USA angenommen, jedoch durch den UCC überholt)

= Vorentwurf eines französischen Code civil, Buch I, Buch IV (1955)

$=$ Civil Code of California von 1872

= Dänisches Gesetz über Minderjährigkeit und Vormundschaft vom 30. 6. 1922

$=$ Deutsches Bürgerliches Gesetzbuch von 1896

$=$ Englischer Sale of Goods Act, 1893

$=$ Niederländischer Entwurf eines neuen bürgerlichen Gesetzbuches (Buch 1-4) von 1954, Buch 6 von 1961

= Französischer Code civil von 1804

$=$ Italienischer Codice civile von 1942

= Louisiana Civil Code von 1870

= Niederländisches Burgerlijk Wetboek von 1837

= Norwegisches Gesetz über Vormundschaft und über Minderjährige vom 22. 4. 1927

= Oisterreichisches Allgemeines Bürgerliches Gesetzbuch von 1811

$=$ Schwedisches Elterngesetz vom 10. 6. 1949

= Schweizerisches Obligationenrecht von 1911

= Schweizer Zivilgesetzbuch von 1907

= Dänisches Gesetz über den Kauf vom 6. 4. 1906 Isländisches Gesetz über den Kauf vom 11.7.1911 Norwegisches Gesetz über den Kauf vom 24.5.1907 Schwedisches Gesetz über Kauf und Tausch von Fahrnis vom 20.6. 1905

= Dänisches Gesetz über Verträge und Rechtsgeschäfte auf dem Gebiet des Vermögensrechts vom 8.5.1917 Finnisches Gesetz über Rechtsgeschäfte auf dem Gebiet des Vermögensrechts vom 13. 6. 1929

Norwegisches Gesetz über den Abschluß von Verträgen, über die Vollmacht und über ungültige Willenserklärung vom 31, 5. 1918

Schwedisches Gesetz über Verträge und andere Rechtsgeschäfte auf dem Gebiete des Vermögensrechts vom 11. 6. 1915

= Spanischer Código civil von 1889

= Spanischer Código de comercio von 1885

= Ungarisches Zivilgesetzbuch von 1959 
